\title{
Prognostic and clinicopathologic significance of SIRT1 expression in hepatocellular carcinoma
}

\author{
Hongyuan Jiang ${ }^{1, *}$, Xiao Zhang ${ }^{2, *}$, Yuquan Tao ${ }^{1}$, Liang Shan ${ }^{1}$, Qijun Jiang ${ }^{1}$, Yongchun \\ $\mathrm{Yu}^{1}$, Feng $\mathrm{Cai}^{3}$ and Lifang $\mathrm{Ma}^{3}$ \\ ${ }^{1}$ Shanghai Municipal Hospital of Traditional Chinese Medicine Affiliated to Shanghai TCM University, Shanghai, 200071, China \\ ${ }^{2}$ Department of Clinical Laboratory Medicine, Shanghai Tenth People's Hospital of Tongji University, Shanghai, 200072, China \\ ${ }^{3}$ Department of Clinical Laboratory Medicine, Shanghai Municipal Hospital of Traditional Chinese Medicine Affiliated to \\ Shanghai TCM University, Shanghai, 200071, China \\ *These authors have contributed equally to this work \\ Correspondence to: Feng Cai, email: 1182@szy.sh.cn \\ Lifang Ma, email: malifang0606118@126.com
}

Keywords: meta-analysis, prognosis, clinical value, HCC, hazard ratio

Received: September 22, $2016 \quad$ Accepted: November 19, $2016 \quad$ Published: December 22, 2016

Copyright: Jiang et al. This is an open-access article distributed under the terms of the Creative Commons Attribution License 3.0 (CC BY 3.0), which permits unrestricted use, distribution, and reproduction in any medium, provided the original author and source are credited.

\section{ABSTRACT}

The clinical value of SIRT1 in hepatocellular carcinoma (HCC) remains controversial. This meta-analysis was performed to investigate the prognostic and clinicopathological significance of the histone deacetylase SIRT1 in HCC. Pooled hazard ratios (HRs) for survival outcomes and pooled odds ratios (ORs) for clinical parameters associated with SIRT1 were calculated in nine studies using Review Manager. Meta-analysis showed that increased SIRT1 expression is associated with poor overall survival (OS) (HR=1.82, 95\% confidence interval (CI): 1.49-2.22, $P<0.00001)$ and disease-free survival (DFS) ( HR=1.44, 95\%CI: 1.06-1.96, $P=0.02)$ in HCC. Increased expression of SIRT1 is more common in female than male HCC patients ( $O R=0.47,95 \% C I: 0.32-0.70, P=0.0001)$. The increased SIRT1 expression correlates with hepatitis $B$ virus (HBV) infection ( $O R=1.63,95 \% C I$ : 1.04-2.57, $P=0.03$ ), large tumor size ( $\mathrm{OR}=1.81,95 \% \mathrm{CI}$ : 1.05-3.13, $\mathrm{P}=0.03)$, high $\mathrm{p} 53$ expression (OR=2.71, 95\%CI: 1.39-5.29, $P=0.003$ ), high levels of alpha-fetoprotein (AFP; cutoff value: 400 $\mathrm{ng} / \mathrm{ml}, \mathrm{OR}=1.84,95 \% \mathrm{CI}: 1.26-2.69, \mathrm{P}=0.002)$, and tumor stage $(\mathrm{OR}=1.72,95 \% \mathrm{CI}$ : 1.27-2.32, $P=0.0004$ ). Re-sampling statistics for 5,000,000 samples revealed that increased SIRT1 expression is associated with higher TNM stage $(\mathrm{OR}=1.70,95 \% \mathrm{CI}$ : 1.69-1.70, $P<0.00001)$. These results indicate that SIRT1 is a new biomarker off HCC as well as a potentially effective therapeutic target.

\section{INTRODUCTION}

Primary liver cancer is the sixth most commonly occurring cancer in the world, and the second largest contributor to cancer mortality [1]. Most (70\% to 90\%) primary liver cancers are hepatocellular carcinoma (HCC) [2], the third leading cause of cancer-related death [3]. Most HCC risk factors (chronic infection with hepatitis B (HBV) and/or C virus (HCV) and alcoholic liver disease) operate by promoting the development of cirrhosis [4]. The treatment options for HCC are limited, mainly because of the lack of reliable biomarkers.
Silent information regulator 1 (SIRT1) is a member of mammalian sirtuin protein family, which are histone deacetylases that utilize NAD + as a cofactor $[5,6]$. SIRT1 promotes or inhibits many biological processes, including regulation of gene expression, cellular metabolism, stress response, aging, and chemo-resistance [7]. Importantly, SIRT1 is thought to promote HCC tumorigenesis. Recent studies have demonstrated that compared with normal liver or surrounding tumor tissues, SIRT1 is strongly overexpressed in human HCC $[6,7]$. SIRT1 facilitates $\mathrm{HCC}$ metastasis by promoting peroxisome proliferatoractivated receptor coactivator $1 \alpha$ (PGC-1 $\alpha)$-mediated 
mitochondrial biogenesis [8]. In experimental HCC mouse models or HCC cell lines, SIRT1 overexpression promotes metastasis through epithelial-mesenchymal transition (EMT) [9]. In HCC, SIRT1 can activate telomerase reverse transcriptase (TERT) gene promoter [10], promote YAP/ TEAD4 association [11], and stabilize c-Myc protein [12]. Moreover, microRNA-133b can inhibit HCC progression by directly targeting SIRT1 [13]. SIRT1 inhibition enhances the antitumor effect of doxorubicin [7], cisplatin [14], and irradiation [15]. Recent studies have indicated that increased SIRT1 expression is associated with poor HCC prognosis [7-9, 16-21]. Therefore, we speculated that there might be a significant correlation between the expression of SIRT1 and the clinical outcomes of HCC.

In order to more accurately evaluate the association between the SIRT1 expression and HCC clinical outcomes, we performed this meta-analysis to explore the value of SIRT1 as a potential clinical HCC biomarker.

\section{RESULTS}

\section{Characteristics of included studies}

During primary literature search, 145 studies in PubMed, 228 studies in EMBASE, 115 studies in Web of Science, 68 studies in OVID, and 56 studies in Cochrane Library were found. In Oncomine and The Cancer Genome Atlas (TCGA) database, no data about SIRT1 amplification changes in HCC were reported (Supplementary Figure S1). 363 studies remained after excluding duplicate studies. 354 studies were excluded because they contained no relevant survival or clinical data (Figure 1). Finally, nine studies were included in our meta-analysis (Table 1) [7-9, 16-21]. The studies were published from 2011 to 2016, and included 1435 patients from Asia. High expression of SIRT1 was present in $54.2 \%$ of the patients. Eight studies used IHC to examine the SIRT1 expression, and one study used western blotting. Eight studies reported overall survival (OS) data and three studies reported disease free survival (DFS) data. Eight studies reported the association between SIRT1 high expression and poor prognosis in HCC. Five of these eight studies reported a significant association $(\mathrm{P}<0.05)$. The detailed information is displayed in Supplementary Table S1.

\section{Meta-analysis for prognostic value}

The combined analysis of 8 studies showed that high expression of SIRT1 was associated with poor prognosis in OS in HCC patients (hazard Ratio $(\mathrm{HR})=1.82,95 \%$ confidence interval (CI): 1.49-2.22, $\mathrm{P}<0.00001)$ without significant heterogeneity $\left(\mathrm{I}^{2}=12 \%, \mathrm{P}=0.34\right)$ (Figure 2 ). As for 3 studies reporting DFS, increased SIRT1 expression was also associated with poor HCC prognosis $(\mathrm{HR}=1.44,95 \% \mathrm{CI}: 1.06-1.96, \mathrm{P}=0.02)$ without significant heterogeneity $\left(\mathrm{I}^{2}=7 \%, \mathrm{P}=0.34\right)$ (Figure 3 ).

\section{Quality assessment}

The quality of the studies was assessed by the Newcastle-Ottawa Quality Assessment Scale (NOS)

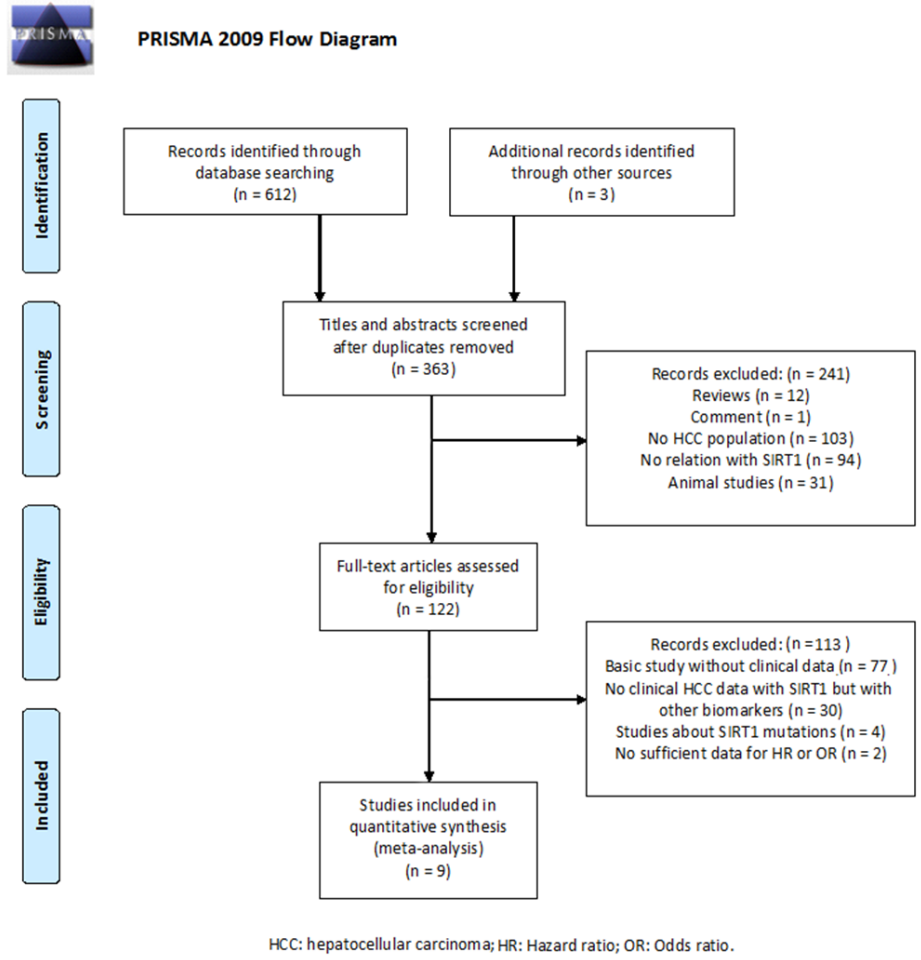

Figure 1: Flow diagram of literature search and selection. 
Table 1: Characteristics of included studies in the meta-analysis

\begin{tabular}{|c|c|c|c|c|c|c|c|c|c|}
\hline Study & Year & $\begin{array}{c}\text { Total subject } \\
\text { (Male/ } \\
\text { Female) }\end{array}$ & Age & $\begin{array}{c}\text { High } \\
\text { expression }\end{array}$ & $\begin{array}{c}\text { Low } \\
\text { expression }\end{array}$ & $\begin{array}{l}\text { TNM } \\
\text { stage }\end{array}$ & Method & $\begin{array}{l}\text { Follow- } \\
\text { up time } \\
\text { (month) }\end{array}$ & $\begin{array}{c}\text { Type of } \\
\text { Survival } \\
\text { data }\end{array}$ \\
\hline Chen [7] & 2012 & $172(142 / 30)$ & $55.9($ mean $)$ & 95 & 77 & I-III & IHC & 125 & OS \\
\hline Li [8] & 2016 & $72(65 / 7)$ & 50.1(mean) & 41 & 31 & I-III & IHC & 60 & DFS OS \\
\hline Наo [9] & 2014 & $99(89 / 10)$ & $\begin{array}{l}\leq 5055 \text { patients } \\
>5044 \text { patients }\end{array}$ & 76 & 23 & I-IV & IHC & 130 & OS \\
\hline Song [16] & 2014 & $300(267 / 33)$ & $53.0($ mean $)$ & 155 & 145 & I-IV & IHC & 64 & OS \\
\hline Choi [17] & 2011 & $90(77 / 13)$ & $\begin{array}{l}<6048 \text { patients } \\
\geq 6042 \text { patients }\end{array}$ & 50 & 40 & I-IV & IHC & NR & NR \\
\hline Jang [18] & 2012 & $154(132 / 22)$ & $\begin{array}{l}<5566 \text { patients } \\
\geq 5588 \text { patients }\end{array}$ & 55 & 99 & I-IV & IHC & 140 & DFS OS \\
\hline Zhang [19] & 2015 & 252(NR) & NR & 153 & 98 & I-IV & $\begin{array}{l}\text { Western } \\
\text { Blotting }\end{array}$ & 125 & DFS OS \\
\hline Cheng [20] & 2015 & $148(\mathrm{NR})$ & NR & 77 & 71 & I-III & IHC & 80 & OS \\
\hline Liu [21] & 2016 & $148(128 / 20)$ & $\begin{array}{l}<5093 \text { patients } \\
\geq 5055 \text { patients }\end{array}$ & 76 & 72 & I-III & IHC & 80 & OS \\
\hline
\end{tabular}

Abbreviations: NR, no report; IHC, immunohistochemistry; OS, overall survival; DFS, disease-free survival.

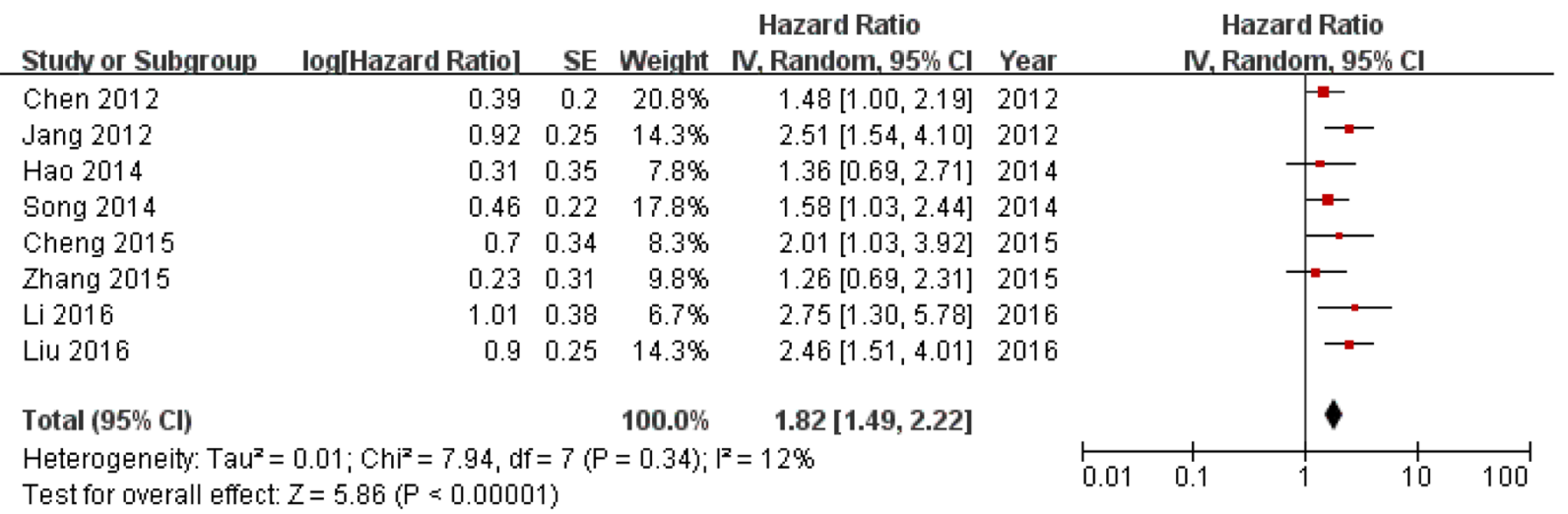

Figure 2: Forest plot of HRs for the association of SIRT1 expression in HCC with OS.

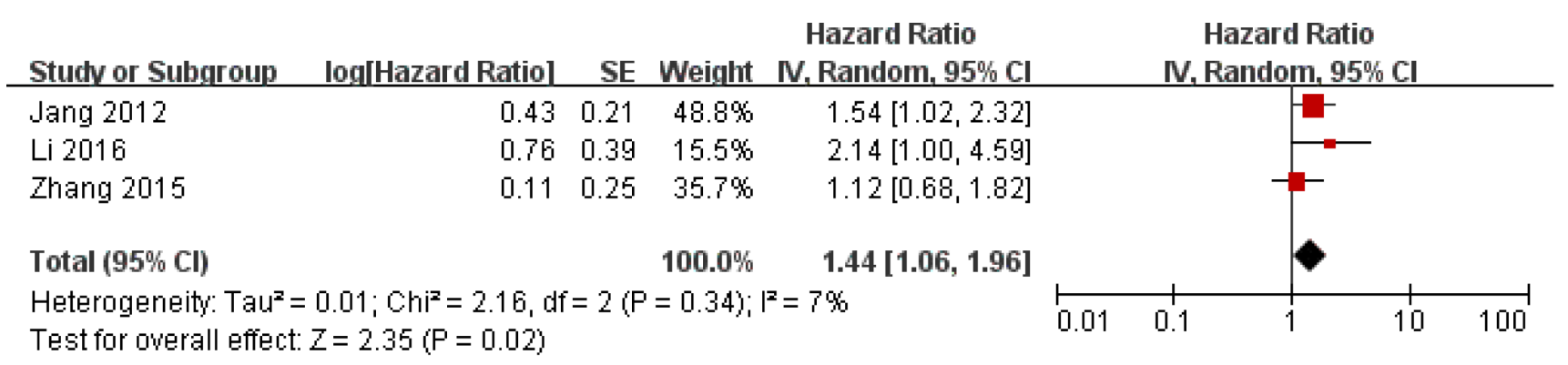

Figure 3: Forest plot of HRs for the association of SIRT1 expression in HCC with DFS. 
Table 2: A summary of hazard ratios (HRs) for the subgroup analyses of SIRT1 expression in HCC patients

\begin{tabular}{lccccc}
\hline Subgroups & Patients number & HR & 95\%CI & P value & Subgroup differences \\
\hline Studies before 2015 & 725 & 1.69 & $1.31-2.18$ & $<0.0001$ & \\
Studies in 2015 and 2016 & 620 & 2.03 & $1.45-2.84$ & $<0.0001$ & $\mathrm{P}=0.39$ \\
Subjects $<150$ & 467 & 2.13 & $1.56-2.90$ & $<0.00001$ & \\
Subjects $\geq 150$ & 878 & 1.66 & $1.27-2.17$ & 0.0002 & $\mathrm{P}=0.24$ \\
Follow-up $<100$ months & 668 & 2.03 & $1.55-2.66$ & $<0.00001$ & \\
Follow-up $\geq 100$ months & 677 & 1.63 & $1.20-2.22$ & 0.002 & $\mathrm{P}=0.30$ \\
high quality studies & 626 & 1.76 & $1.29-2.39$ & 0.0003 & \\
other studies & 719 & 1.9 & $1.40-2.57$ & $<0.0001$ & $\mathrm{P}=0.73$ \\
\hline
\end{tabular}

Abbreviations: HR, hazard ratio; CI, confidence interval.

(http://www.ohri.ca/programs/clinical_epidemiology/ nosgen.pdf) [22]. Three studies with scores higher than 6 were deemed as high quality studies (Supplementary Table S2).

\section{Subgroup analysis}

The results of subgroup analysis are summarized in Table 2. The subgroup analysis was performed according to publication year, subjects in study, the length of follow-up time, and quality of the studies. Except for the association between SIRT1 expression and the patients in the subgroup, the difference between subgroups could be also calculated by Review Manager. High SIRT1 expression was associated with poor HCC prognosis both in studies before $2015(\mathrm{HR}=1.69,95 \% \mathrm{CI}$ : 1.31-2.18, $\mathrm{P}<0.0001)$, and in studies published between 2015 and 2016 (HR=2.03, 95\%CI: $1.45-2.84, \mathrm{P}<0.0001)$. No significant difference between subgroups was found $(\mathrm{P}=0.39)$. As for the subjects in the study, no significant difference between subgroups was found (Subjects $<150$ : $\mathrm{HR}=2.13,95 \% \mathrm{CI}: 1.56-2.90, \mathrm{P}<0.00001$; Subjects $\geq 150$ : HR $=1.66,95 \%$ CI: $1.27-2.17, \mathrm{P}=0.0002$; Subgroup difference: $\mathrm{P}=0.24)$. Regarding the association between follow-up time and prognosis, high SIRT1 expression was associated with poor HCC prognosis both in studies with follow-up time $<100$ months $(\mathrm{HR}=2.03,95 \% \mathrm{CI}$ : $1.55-2.66, \mathrm{P}<0.00001)$ and in studies with follow-up time $\geq 100$ months (HR=1.63, 95\%CI: 1.20-2.22, $\mathrm{P}<0.002$ ); no significant difference was observed $(\mathrm{P}=0.39)$. As for the three high quality studies, the high SIRT1 expression was associated with poor $\mathrm{HCC}$ prognosis $(\mathrm{HR}=1.76$, 95\%CI: $1.29-2.39, \mathrm{P}=0.0003)$. Moreover, as for the other five studies, high SIRT1 expression was also associated with poor $\mathrm{HCC}$ prognosis $(\mathrm{HR}=1.90,95 \% \mathrm{CI}: 1.40-2.57$, $\mathrm{P}<0.0001$ ); no significant difference between subgroups was found $(\mathrm{P}=0.73)$.

\section{Sensitivity analysis}

Sensitivity analysis was performed by omitting one study at a time and calculating the pooled HRs again [19]. In each sensitivity group, the $P$ value for testing the statistical significance of the association was not changed and heterogeneity was not observed $\left(\mathrm{I}^{2}<50 \%, \mathrm{P}>0.1\right)$. Thus, the stability of the meta-analysis was not influenced by any single independent study (Table 3 ).

\section{Publication bias}

Publication bias of the included studies was evaluated by Begg's funnel plot and Egger's test. The detailed results are displayed in Table 4. Since all $P$ values were greater than 0.05 , no significant publication bias was present.

\section{Clinicopathologic analysis}

Eight studies were included in the clinicopathologic analysis. Higher expression of SIRT1 was more common in female HCC patients than male patients (odds ratio $(\mathrm{OR})=0.47,95 \% \mathrm{CI}$ : $0.32-0.70, \mathrm{P}=0.0001$ ) (Supplementary Figure S2). In addition, increased SIRT1 expression was a more common phenomenon in HBVinfected HCC patients than in non-HBV HCC patients $(\mathrm{OR}=1.63,95 \% \mathrm{CI}$ : 1.04-2.57, $\mathrm{P}=0.03)$ (Supplementary Figure S3). Higher expression of SIRT1 was associated with larger tumor size $(\mathrm{OR}=1.81,95 \% \mathrm{CI}$ : 1.05-3.13, $\mathrm{P}=0.03$ ) (Supplementary Figure S4), and with increased expression of $\mathrm{p} 53$ (OR=2.71, 95\% CI: 1.39-5.29, $\mathrm{P}=0.003)$ (Supplementary Figure S5). Moreover, higher expression of SIRT1 was associated with increased alpha-fetoprotein (AFP) levels. When the cutoff value was set to $400 \mathrm{ng} / \mathrm{ml}$, the association was significant $(\mathrm{OR}=1.84,95 \% \mathrm{CI}: 1.26$ 2.69, $\mathrm{P}=0.002$ ) (Supplementary Figure S6). However, 
Table 3: The influence of individual study on the pooled estimate (OR) for overall survival

\begin{tabular}{lcccccc}
\hline Studies omitted & Year & HR & 95\%CI & P value & Hetorogeneity & P value \\
\hline None & & 1.82 & $1.49-2.22$ & $<0.00001$ & 12 & 0.34 \\
Chen [7] & 2012 & 1.92 & $1.54-2.40$ & $<0.00001$ & 9 & 0.36 \\
Li [8] & 2016 & 1.76 & $1.44-2.16$ & $<0.00001$ & 10 & 0.35 \\
Hao [9] & 2014 & 1.87 & $1.51-2.31$ & $<0.00001$ & 17 & 0.3 \\
Song [16] & 2014 & 1.88 & $1.48-2.37$ & $<0.00001$ & 20 & 0.28 \\
Jang [18] & 2012 & 1.71 & $1.40-2.09$ & $<0.00001$ & 0 & 0.43 \\
Zhang [19] & 2015 & 1.89 & $1.54-2.31$ & $<0.00001$ & 7 & 0.38 \\
Cheng [20] & 2015 & 1.8 & $1.44-2.26$ & $<0.00001$ & 23 & 0.27 \\
Liu [21] & 2016 & 1.72 & $1.40-2.11$ & $<0.00001$ & 3 & 0.4 \\
\hline
\end{tabular}

Abbreviations: HR, hazard ratio; CI, confidence interval.

Table 4: Begg's funnel plot and Egger's test of publication bias on the relationships between miR-200c and prognostic value in cancer

\begin{tabular}{|c|c|c|c|c|c|}
\hline & \multirow{2}{*}{$\begin{array}{c}\text { Patient } \\
\text { number }\end{array}$} & \multirow{2}{*}{$\frac{\text { Begg's funnel plot }}{\mathrm{Z} \text { test for plot asymmetry }}$} & \multirow{2}{*}{ P value } & \multicolumn{2}{|c|}{ Egger's test } \\
\hline & & & & t value & P value \\
\hline \multicolumn{6}{|l|}{ OS } \\
\hline Overall & 1435 & 0.25 & 0.803 & 0.48 & 0.645 \\
\hline Studies before 2015 & 725 & 0.34 & 0.734 & 0.06 & 0.961 \\
\hline Studies in 2015 and 2016 & 620 & -0.34 & 1 & -0.09 & 0.934 \\
\hline Subjects $<150$ & 467 & 0.34 & 0.734 & -0.5 & 0.665 \\
\hline Subjects $\geq 150$ & 878 & -0.34 & 1 & 0 & 0.999 \\
\hline Follow-up $<100$ months & 668 & 0.34 & 0.734 & 1.12 & 0.381 \\
\hline Follow-up $\geq 100$ months & 677 & -0.34 & 1 & -0.32 & 0.782 \\
\hline \multicolumn{6}{|l|}{ DFS } \\
\hline Overall & 478 & 0 & 1 & 0.59 & 0.659 \\
\hline
\end{tabular}

Abbreviations: OS, overall survival; DFS, disease-free survival.

when the cutoff value was set to $100 \mathrm{ng} / \mathrm{ml}$, no association was found $(\mathrm{OR}=1.67,95 \% \mathrm{CI}$ : $0.91-3.05, \quad \mathrm{P}=0.09)$ (Supplementary Figure S7). Increased SIRT1 expression was also associated with the increased TNM stage (stage III-IV vs stage I-II, OR=1.91, 95\%CI: 1.12-3.26, $\mathrm{P}=0.02$ ) (Supplementary Figure S8). However, when evaluating cirrhosis and age, no significant association was found (Supplementary Figures S9 and S10).

\section{Re-sampling statistics}

Bootstrap re-sampling procedures were applied to investigate the association between SIRT1 expression and TNM stage in order to get robust and reproducible results [23] (Supplementary Excel File S1). One randomly generated results are summarized in Supplementary Excel File S2. The distribution of odds ratios was between 1.43 and 2.045, suggesting that the increased SIRT1 expression 
is associated with higher TNM stage. When evaluating 5,000,000 samples, the odds ratio was 1.70 (95\%CI: 1.69 $1.70, \mathrm{P}<0.00001$ ) (Figure 4).

\section{DISCUSSION}

SIRT1, homologue of the yeast Sir2 protein, is the most researched sirtuin in the mammalian sirtuin family [24]. SIRT1 activates transcription silencing, DNA repair, recombination of ribosomal DNA, nuclear receptors to stimulate mitochondrial biogenesis, circadian clock, and lipid homeostasis [25]. In HCC, SIRT1 is aberrantly overexpressed and activates TERT gene promoter [10], YAP/TEAD4 association [11], c-Myc stabilization [12], NF-kB [26], wnt/ $\beta$-catenin [13], and PI3K/AKT [27] signaling to stimulate cell proliferation and metastasis [7, 28, 29]. Moreover, SIRT1 induces expression of the transcription factor SOX2 to stimulate the self-renewal of liver cancer stem cells [21]. Due to the importance of SIRT1 in biological processes and HCC progression, it is urgent to uncover the mechanisms of how SIRT1 regulates the HCC progression, and to evaluate the clinical value of SIRT1. In our meta-analysis, we analyzed eight studies in Asian population between 2012 and 2016, and found that increased SIRT1 expression correlated with poor prognosis in $\mathrm{HCC}$ patients $(\mathrm{HR}=1.82,95 \% \mathrm{CI}$ : 1.49-2.22, $\mathrm{P}<0.00001)$.

Deacetylase activity of SIRT1 is essential for the SIRT1 oncogenic function in HCC. When the deacetylation domain of SIRT1 is mutated, HCC cell proliferation and colony formation are inhibited [7]. For instance, LC3 can be deacetylated by SIRT1 to induce autophagy in HepG2 cells [30]. Moreover, p53 is the most widely studied target of SIRT1, and p53 deacetylation by SIRT1 can repress cellular senescence and apoptosis, thus stimulating tumorigenesis in HCC [5]. Inactivated SIRT1 (no phosphorylation on Ser 47) can bind to mutated p53, thus activating AMPK/mTOR pathway to exert the carcinogenic effects in HCC [19]. Our clinicopathologic analysis indicates that increased expression of SIRT1 correlates with high expression of p53 in $\mathrm{HCC}(\mathrm{OR}=2.71,95 \% \mathrm{CI}: 1.39-5.29, \mathrm{P}=0.003)$. Hepatitis $\mathrm{B}$ virus (HBV) is one of the main causes of HCC [31]. SIRT1 is upregulated in HBV-infected cells, and its transcription and replication can be upregulated by SIRT1 in HCC $[32,33]$. In our clinicopathologic analysis, we also found that the increased SIRT1 expression was more common in HBV-infected HCC $(\mathrm{OR}=1.63,95 \% \mathrm{CI}: 1.04-2.57, \mathrm{P}=0.03)$.

Although we have comprehensively analyzed the prognostic and clinicopathologic value of SIRT1 in HCC, some limitations remain in our study. First, the SIRT1 expression was analyzed by IHC or western blotting, with no unified standard or cutoff value. In the study by Chen et. al [7], dark brown nuclear staining in more than $5 \%$ of cancer cells was defined as positive. In the study by Hao et. al [9] and Choi et. al [17], dark brown nuclear staining in more than $10 \%$ of cancer cells was defined as positive. In the study by Jang et. al [18], dark brown nuclear staining in more than $30 \%$ of cancer cells was defined as positive. In the study by Song et. al [16], H-score system was used, and more than $30 \%$ of positively stained cells was defined as positive. In the study by Li et. al [8], the definition of SIRT1 positive expression was not clearly stated. In other studies [1921], the standards were not reported. Second, the sample size in the subgroup analysis was not big enough; thus, the statistic power was limited. Third, no study with Caucasian population was included in our meta-analysis. Although there are multiple studies about SIRT1 in HCC performed by European or American scientists, these studies focus on molecular mechanisms, and not enough clinical samples were tested.

Nevertheless, this is the first meta-analysis study that indicates that increased SIRT1 expression is associated with poor prognosis in HCC. Moreover, we found that SIRT1 expression is associated with sex, HBV-infection, AFP levels, tumor size, TNM stage, and p53 expression. Our study indicates that SIRT1 expression might serve as a potential therapeutic target and prognostic marker in HCC.

\begin{tabular}{|c|c|c|c|c|c|c|c|c|c|c|}
\hline Studv or Subgroup & \multicolumn{2}{|c|}{ Stage III-IV } & \multicolumn{2}{|c|}{ Stage I-II } & \multicolumn{2}{|r|}{ Odds Ratio } & \multicolumn{4}{|c|}{ Odds Ratio } \\
\hline Re-sampling & 1269260 & 2182267 & 1268304 & 2817733 & $100.0 \%$ & $1.70[1.69,1.70]$ & & & & \\
\hline Total $(95 \% \mathrm{Cl})$ & & 2182267 & & 2817733 & $100.0 \%$ & $1.70[1.69,1.70]$ & & & 1 & \\
\hline Total events & 1269260 & & 1268304 & & & & & & & \\
\hline $\begin{array}{l}\text { Heterogeneity: Not a } \\
\text { Test for overall effec }\end{array}$ & $\begin{array}{l}\text { plicable } \\
Z=290.82\end{array}$ & $(\mathrm{P}=0.000$ & & & & & 0.01 & 0.1 & 10 & 100 \\
\hline
\end{tabular}

Figure 4: Meta-analysis evaluating SIRT1 expression for TNM stage in 1000 re-sampling groups containing five million samples. 


\section{MATERIALS AND METHODS}

\section{Literature search}

We followed the PRISMA statement in our metaanalysis (Supplementary Checklist S1). PubMed, EMBASE, Web of Science, Cochrane Library and OVID databases were searched since their inception up to October 9th 2016, without language and publication restrictions. The key words of the search were ("Sirtuin 1 [MeSH]" OR "SIR2" OR "SIR2L1" OR "SIR2alpha" OR "silent mating type information regulation 2 homolog 1 " OR "NAD-dependent deacetylase sirtuin-1" OR "sirtuin (silent mating type information regulation 2 homolog) 1" OR "SIRT1 protein, human"OR "SIR2L1 protein, human" OR "sirtuin 1, human" OR "Sir2-like 1 protein, human" OR "sirtuin (silent mating type information regulation 2 homolog) 1 (S. cerevisiae), human" OR "SIRT1" OR "SIRT 1" OR "SIRT-1" OR "Sirtuin 1" OR "Sirtuin-1" OR "Silent information regulator 1") AND ("Liver Neoplasms [MeSH]" OR "Carcinoma, Hepatocellular [MeSH]" OR "liver cancer" OR "hepatocarcinoma" OR "hepatocellular carcinoma" OR "hepatocellular cancer" OR "HCC" OR "liver AND cancer" OR "liver AND neoplasms"). We also screened review articles [5, 34, 35] and their reference lists to complete our research. Oncomine (User ID: 1zhangxiao@tongji.edu.cn) and TCGA (analyzed by cBioPortal $[36,37]$ ) were searched to make our data complete. H. Jiang and X. Zhang independently searched the databases, excluded the irrelevant studies with double check and disagreements were resolved by consensus of all the authors. All retrieved articles were managed by the EndNote X6 software (available at the website www. endnote.com, Thomson Reuters).

\section{Selection criteria}

The articles were included if they: (1) Proved prognostic or clinicopathologic value of the SIRT1 expression in HCC; (2) More than 30 patients were enrolled in studies; (3) Studies provided sufficient data to obtain the odds ratio (OR) or hazard ratio (HR) and 95\% confidence intervals (CI). H. Jiang and X. Zhang scanned the titles and abstracts to exclude irrelevant studies, and the full articles were examined by all authors in detail. No overlapping patient populations were included in our meta-analysis.

\section{Data extraction}

H. Jiang and $X$. Zhang independently extracted the following data: first author, year of publication, race of publication, number of patients with SIRT1 high expression and low expression, method of SIRT1 expression, follow-up time and type of survival data. Since multivariate analysis takes confounding factors into consideration and is more accurate, it would be selected when univariate and multivariate analysis were both present in the study [38]. If HR was not reported in the study, Engauge Digitizer version 4.1 (free software downloaded from http://sourceforge.net) was used to read the Kaplan-Meier survival curves to obtain the HRs and their $95 \%$ CIs by two different authors (H. Jiang and X. Zhang). If the essential data was not reported in the study, we asked corresponding authors for additional information.

\section{Quality assessment}

The Newcastle-Ottawa Quality Assessment Scale (NOS) (http://www.ohri.ca/programs/clinical epidemiology/nosgen.pdf) was used to assess the quality of the study [22]. The score was from 0 to 9 , and the study with a score higher than 6 was deemed as a high quality study.

\section{Statistical analysis}

Hazard ratios (HRs) and corresponding 95\% confidence intervals (CIs) were combined to evaluate the value of SIRT1 expression on HCC prognosis. An $\mathrm{HR}>1$ suggested poor prognosis in patients with high expression of SIRT1. P value $<0.05$ suggested significant association. The association between SIRT1 expression and clinicopathology significance for HCC was measured by odds ratios (ORs) and 95\% CIs. We extracted the data from Kaplan-Meier survival curve using EngaugeDigitizer version 7.2 if there was no direct data in the study [39]. Two authors (H. Jiang and X. Zhang) checked the curves independently to reduce reading variability. Cochran's Q test and Higgins I-squared statistic were used to measure the heterogeneity among the studies. $\mathrm{I}^{2}$ $\geq 50 \%$ and $\mathrm{P}$ value for Cochran's $\mathrm{Q}$ test $<0.1$ suggested significant heterogeneity. Random-effects models were selected to avoid the influence of heterogeneity. These statistical analyses were performed by Review Manager Version 5.1 software(http://ims.cochrane.org/revman) and the publication bias was measured by $\mathrm{R}$ (http://cran.rproject.org/bin/windows/base). Only the biomarkers that more than two studies reported could be included in our clinicopathologic analysis. Bootstrap re-sampling procedure was used to validate the association between SIRT1 expression and TNM stage as we described previously [23]. The re-sampling statistic program was displayed in Supplementary Excel File S1. A randomly produced result, the ORs containing all samples and the ORs distribution of each re-sample group were shown in Supplementary Excel File S2.

\section{CONFLICTS OF INTEREST}

The authors declare no conflicts of interest. 


\section{GRANT SUPPORT}

This study was supported by the National Natural Science Foundation of China (81472124).

\section{REFERENCES}

1. Bray F, Ferlay J, Laversanne M, Brewster DH, Gombe Mbalawa C, Kohler B, Pineros M, Steliarova-Foucher E, Swaminathan R, Antoni S, Soerjomataram I, Forman D. Cancer Incidence in Five Continents: Inclusion criteria, highlights from Volume $\mathrm{X}$ and the global status of cancer registration. Int J Cancer. 2015; 137:2060-71. doi: 10.1002/ ijc. 29670 .

2. Torre LA, Bray F, Siegel RL, Ferlay J, Lortet-Tieulent J, Jemal A. Global cancer statistics, 2012. CA Cancer J Clin. 2015; 65:87-108. doi: 10.3322/caac.21262.

3. El-Serag HB. Hepatocellular carcinoma. N Engl J Med. 2011; 365:1118-27. doi: 10.1056/NEJMra1001683.

4. El-Serag HB, Kanwal F. Epidemiology of hepatocellular carcinoma in the United States: where are we? Where do we go? Hepatology. 2014; 60:1767-75. doi: 10.1002/ hep. 27222 .

5. Wu Y, Meng X, Huang C, Li J. Emerging role of silent information regulator 1 (SIRT1) in hepatocellular carcinoma: a potential therapeutic target. Tumour Biol. 2015; 36:4063-74. doi: 10.1007/s13277-015-3488-x.

6. Chen J, Zhang B, Wong N, Lo AW, To KF, Chan AW, Ng MH, Ho CY, Cheng SH, Lai PB, Yu J, Ng HK, Ling MT, et al. Sirtuin 1 is upregulated in a subset of hepatocellular carcinomas where it is essential for telomere maintenance and tumor cell growth. Cancer Res. 2011; 71:4138-49. doi: 10.1158/0008-5472.CAN-10-4274.

7. Chen HC, Jeng YM, Yuan RH, Hsu HC, Chen YL. SIRT1 promotes tumorigenesis and resistance to chemotherapy in hepatocellular carcinoma and its expression predicts poor prognosis. Ann Surg Oncol. 2012; 19:2011-9. doi: 10.1245/ s10434-011-2159-4.

8. Li Y, Xu S, Li J, Zheng L, Feng M, Wang X, Han K, Pi H, Li M, Huang X, You N, Tian Y, Zuo G, et al. SIRT1 facilitates hepatocellular carcinoma metastasis by promoting PGC1alpha-mediated mitochondrial biogenesis. Oncotarget. 2016; 7:29255-74. doi: 10.18632/oncotarget.8711.

9. Hao C, Zhu PX, Yang X, Han ZP, Jiang JH, Zong C, Zhang XG, Liu WT, Zhao QD, Fan TT, Zhang L, Wei LX. Overexpression of SIRT1 promotes metastasis through epithelial-mesenchymal transition in hepatocellular carcinoma. BMC Cancer. 2014; 14:978. doi: 10.1186/1471-2407-14-978.

10. Zhang B, Chen J, Cheng AS, Ko BC. Depletion of sirtuin 1 (SIRT1) leads to epigenetic modifications of telomerase (TERT) gene in hepatocellular carcinoma cells. PLoS One. 2014; 9:e84931. doi: 10.1371/journal.pone.0084931.
11. Mao B, Hu F, Cheng J, Wang P, Xu M, Yuan F, Meng S, Wang Y, Yuan Z, Bi W. SIRT1 regulates YAP2-mediated cell proliferation and chemoresistance in hepatocellular carcinoma. Oncogene. 2014; 33:1468-74. doi: 10.1038/ onc.2013.88.

12. Menssen A, Hydbring P, Kapelle K, Vervoorts J, Diebold J, Luscher B, Larsson LG, Hermeking H. The c-MYC oncoprotein, the NAMPT enzyme, the SIRT1-inhibitor DBC1, and the SIRT1 deacetylase form a positive feedback loop. Proc Natl Acad Sci U S A. 2012; 109:E187-96. doi: 10.1073/pnas.1105304109.

13. Tian Z, Jiang H, Liu Y, Huang Y, Xiong X, Wu H, Dai X. MicroRNA-133b inhibits hepatocellular carcinoma cell progression by targeting Sirt1. Exp Cell Res. 2016; 343:135-47. doi: 10.1016/j.yexcr.2016.03.027.

14. Liang XJ, Finkel T, Shen DW, Yin JJ, Aszalos A, Gottesman MM. SIRT1 contributes in part to cisplatin resistance in cancer cells by altering mitochondrial metabolism. Mol Cancer Res. 2008; 6:1499-506. doi: 10.1158/1541-7786. MCR-07-2130.

15. Xie Y, Zhang J, Ye S, He M, Ren R, Yuan D, Shao C. SirT1 regulates radiosensitivity of hepatoma cells differently under normoxic and hypoxic conditions. Cancer Sci. 2012; 103:1238-44. doi: 10.1111/j.1349-7006.2012.02285.x.

16. Song S, Luo M, Song Y, Liu T, Zhang H, Xie Z. Prognostic role of SIRT1 in hepatocellular carcinoma. J Coll Physicians Surg Pak. 2014; 24:849-54. doi: 11.2014/JCPSP.849854.

17. Choi HN, Bae JS, Jamiyandorj U, Noh SJ, Park HS, Jang KY, Chung MJ, Kang MJ, Lee DG, Moon WS. Expression and role of SIRT1 in hepatocellular carcinoma. Oncol Rep. 2011; 26:503-10. doi: 10.3892/or.2011.1301.

18. Jang KY, Noh SJ, Lehwald N, Tao GZ, Bellovin DI, Park HS, Moon WS, Felsher DW, Sylvester KG. SIRT1 and c-Myc promote liver tumor cell survival and predict poor survival of human hepatocellular carcinomas. PLoS One. 2012; 7:e45119. doi: 10.1371/journal.pone.0045119.

19. Zhang ZY, Hong D, Nam SH, Kim JM, Paik YH, Joh JW, Kwon CH, Park JB, Choi GS, Jang KY, Park CK, Kim SJ. SIRT1 regulates oncogenesis via a mutant p53-dependent pathway in hepatocellular carcinoma. J Hepatol. 2015; 62:121-30. doi: 10.1016/j.jhep.2014.08.007.

20. Cheng J, Liu C, Liu L, Chen X, Shan J, Shen J, Zhu W, Qian C. MEK1 signaling promotes self-renewal and tumorigenicity of liver cancer stem cells via maintaining SIRT1 protein stabilization. Oncotarget. 2016; 7:20597-611. doi: 10.18632/oncotarget.7972.

21. Liu L, Liu C, Zhang Q, Shen J, Zhang H, Shan J, Duan G, Guo D, Chen X, Cheng J, Xu Y, Yang Z, Yao C, et al. SIRT1-mediated transcriptional regulation of SOX2 is important for self-renewal of liver cancer stem cells. Hepatology. 2016; 64:814-27. doi: 10.1002/hep.28690.

22. Stang A. Critical evaluation of the Newcastle-Ottawa scale for the assessment of the quality of nonrandomized studies 
in meta-analyses. Eur J Epidemiol. 2010; 25:603-5. doi: 10.1007/s10654-010-9491-z.

23. Wu J, Fang Z, Xu J, Zhu W, Li Y, Yu Y. Prognostic Value and Clinicopathology Significance of MicroRNA-200c Expression in Cancer: A Meta-Analysis. PLoS One. 2015; 10:e128642. doi: 10.1371/journal.pone.0128642.

24. Houtkooper RH, Pirinen E, Auwerx J. Sirtuins as regulators of metabolism and healthspan. Nat Rev Mol Cell Biol. 2012; 13:225-38. doi: 10.1038/nrm3293.

25. Gottlieb S, Esposito RE. A new role for a yeast transcriptional silencer gene, SIR2, in regulation of recombination in ribosomal DNA. Cell. 1989; 56:771-6.

26. Gang D, Hongwei H, Hedai L, Ming Z, Qian H, Zhijun L. The tumor suppressor protein menin inhibits NF-kappaBmediated transactivation through recruitment of Sirt1 in hepatocellular carcinoma. Mol Biol Rep. 2013; 40:2461-6. doi: 10.1007/s11033-012-2326-0.

27. Wang H, Liu H, Chen K, Xiao J, He K, Zhang J, Xiang G. SIRT1 promotes tumorigenesis of hepatocellular carcinoma through PI3K/PTEN/AKT signaling. Oncol Rep. 2012; 28:311-8. doi: 10.3892/or.2012.1788.

28. Bae HJ, Noh JH, Kim JK, Eun JW, Jung KH, Kim MG, Chang YG, Shen Q, Kim SJ, Park WS, Lee JY, Nam SW. MicroRNA-29c functions as a tumor suppressor by direct targeting oncogenic SIRT1 in hepatocellular carcinoma. Oncogene. 2014; 33:2557-67. doi: 10.1038/onc.2013.216.

29. Ding W, You H, Dang H, LeBlanc F, Galicia V, Lu SC, Stiles B, Rountree CB. Epithelial-to-mesenchymal transition of murine liver tumor cells promotes invasion. Hepatology. 2010; 52:945-53. doi: 10.1002/hep.23748.

30. Li X, Wang Y, Xiong Y, Wu J, Ding H, Chen X, Lan L, Zhang H. Galangin Induces Autophagy via Deacetylation of LC3 by SIRT1 in HepG2 Cells. Sci Rep. 2016; 6:30496. doi: 10.1038/srep30496.

31. Torre LA, Bray F, Siegel RL, Ferlay J, Lortet-Tieulent J, Jemal A. Global cancer statistics, 2012. CA Cancer J Clin. 2015; 65:87-108. doi: 10.3322/caac.21262.
32. Curtil C, Enache LS, Radreau P, Dron AG, Scholtes C, Deloire A, Roche D, Lotteau V, Andre P, Ramiere C. The metabolic sensors FXRalpha, PGC-1alpha, and SIRT1 cooperatively regulate hepatitis $\mathrm{B}$ virus transcription. FASEB J. 2014; 28:1454-63. doi: 10.1096/fj.13-236372.

33. Ren JH, Tao Y, Zhang ZZ, Chen WX, Cai XF, Chen K, Ko BC, Song CL, Ran LK, Li WY, Huang AL, Chen J. Sirtuin 1 regulates hepatitis $\mathrm{B}$ virus transcription and replication by targeting transcription factor AP-1. J Virol. 2014; 88:244251. doi: 10.1128/JVI.02861-13.

34. Chang HC, Guarente L. SIRT1 and other sirtuins in metabolism. Trends Endocrinol Metab. 2014; 25:138-45. doi: 10.1016/j.tem.2013.12.001.

35. Yuan H, Su L, Chen WY. The emerging and diverse roles of sirtuins in cancer: a clinical perspective. Onco Targets Ther. 2013; 6:1399-416. doi: 10.2147/OTT.S37750.

36. Gao J, Aksoy BA, Dogrusoz U, Dresdner G, Gross B, Sumer SO, Sun Y, Jacobsen A, Sinha R, Larsson E, Cerami E, Sander C, Schultz N. Integrative analysis of complex cancer genomics and clinical profiles using the cBioPortal. Sci Signal. 2013; 6:pl1. doi: 10.1126/scisignal.2004088.

37. Cerami E, Gao J, Dogrusoz U, Gross BE, Sumer SO, Aksoy BA, Jacobsen A, Byrne CJ, Heuer ML, Larsson E, Antipin Y, Reva B, Goldberg AP, et al. The cBio cancer genomics portal: an open platform for exploring multidimensional cancer genomics data. Cancer Discov. 2012; 2:401-4. doi: 10.1158/2159-8290.CD-12-0095.

38. Gasparrini A, Armstrong B. Multivariate meta-analysis: a method to summarize non-linear associations. Stat Med. 2011; 30:2504-6; discussion 9-10. doi: 10.1002/sim.4226.

39. Guyot P, Ades AE, Ouwens MJ, Welton NJ. Enhanced secondary analysis of survival data: reconstructing the data from published Kaplan-Meier survival curves. BMC Med Res Methodol. 2012; 12:9. doi: 10.1186/1471-2288-12-9. 